\title{
Os sentidos e a urgência de transformação
}

\section{The Senses and the Urgency of Transformation}

Los sentidos y la urgencia de la transformación

Paula Braga*
Universidade Federal do $A B C$, Brasil

https://doi.org/10.22409/poiesis.v20i34.38310

RESUMO: O artigo discute o texto de Hélio Oiticica The Senses Pointing Towards a New Transformation, de 1969, e os conceitos que o embasaram, defendendo a retomada do corpo como potência e proposta para a arte contemporânea.

PALAVRAS-CHAVE: Oiticica; Crelazer; corpo; Merleau-Ponty

\footnotetext{
* Paula Braga é professora na Universidade Federal do ABC (UFABC), autora de Hélio Oiticica: singularidade, multiplicidade (Editora Perspectiva, 2013) e organizadora de Fios Soltos: a arte de Hélio Oiticica (Editora Perspectiva, 2008).

E-mail: paula.p.braga@gmail.com. Orcid: https://orcid.org/0000-0001-7986-6306
} 
ABSTRACT: The article discusses the text by Hélio Oiticica The Senses Pointing Towards a New Transformation, from 1969, and the concepts that supported it, defending the resumption of the body as a power and proposal for contemporary art.

KEYWORDS: Oiticica; Crelazer; body; Merleau-Ponty

RESUMEN: El artículo discute el texto de Hélio Oiticica Los sentidos apuntando hacia una nueva transformación, 1969, y los conceptos que lo respaldaron, defendiendo la recuperación del cuerpo como un poder y una propuesta para el arte contemporáneo.

PALABRAS CLAVE: Oiticica; Crelazer; cuerpo; Merleau-Ponty 


\section{Os sentidos e a urgência de transformação}

O pensamento contrafactual é sempre um pouco desvairado, mas façamos a pergunta mesmo assim: e se, em 1969, a revista Studio International tivesse publicado o texto de Hélio Oiticica The Senses Pointing Towards a New Transformation? Ou seja, e se uma das maiores revistas de arte contemporânea do mundo, no auge das ditaduras militares na América Latina, da Guerra do Vietnam e dos movimentos pelos direitos civis na América do Norte tivesse apoiado a defesa do conhecimento sensível escrita por
Oiticica? A extravagância da pergunta justifica-se por gerar reflexões sobre a possibilidade de retomada da valorização do corpo na arte contemporânea, reativando o pensamento libertário que, em sua versão dos anos 1960 e 1970, eclodiu nos textos de Herbert Marcuse e Paulo Freire, na música de John Lennon e Caetano Veloso, em Hair e Roda Viva. O que pode advir dos fios soltos deixados por esses e outros projetos interrompidos e, ainda assim, tão revolucionários e potencializadores da vida? 
A revista que publicou as três partes do texto de Joseph Kosuth Art after Philosophy entre outubro e dezembro de 1969 , ignorou o artigo de Hélio Oiticica. O texto foi enviado para o editor, mas nunca foi publicado. Folheando as edições da Studio International de 1969 e 1970, percebe-se a variedade de assuntos abordados pela revista: ensaios sobre pintura e escultura, textos sobre arte conceitual, críticas à arte conceitual, artigos mensais sobre arte e tecnologia, artigos sobre arte cinética, ensaios sobre artistas modernistas e a apresentação de vertentes da arte dos anos 1970 que defendiam a arcoerente com a abordagem de Oiticica, como um ensaio sobre o Situacionismo, escrito por Victor Burgin para a edição de novembro de 1969, as experiências do coletivo holandês Event Structure Research Group, publicado em novembro de 1969 e do coletivo inglês Artist Placement Group, em artigo de junho de 1969. Vários desses textos publicados foram escritos por artistas, e a discussão proposta por Hélio Oitici$\mathrm{ca}$, ainda que mais longa do que a maioria dos artigos (exceção feita ao texto de Kosuth), estava de acordo com a linha editorial da Studio International. Uma hipótese para a recusa do artigo são as passagens

intrincadas e de difícil interpretação para o leitor que não acompanhava os textos anteriores do artista, escritas com a liberdade de quem se apropriava livremente de conceitos filosóficos, criava neologismos e novas regras de pontuação, inserindo sinais gráficos no texto, como setas, para indicar o desaguar de uma sentença em outra.

Em sua versão final, o texto The Senses Poiting Towards a New Transformation" tem seis páginas datilografadas, escritas em inglês. Originalmente, foi escrito para ser apresentado no simpósio de Arte Táctil, na Califórnia, em julho de 1969. Depois da apresentação oral, Oiticica retrabalhou o texto, que foi enviado para a Studio International em dezembro de $1969^{1}$, um pouco antes de Oiticica retornar ao Brasil após ter apresentado suas obras na Whitechapel Gallery de Londres (fevereiro a abril de 1969) e dado aulas na universidade de Sussex.

Em carta de dezembro de 1969 para Lygia Clark, Oiticica menciona sua expectativa com a possibilidade de publicação:

\section{0 texto que fiz para o simpósio foi simplificado e corrigido, com ajuda do Guy, e proponho ao Studio International; sairão fotos suas, fantásticas; creio}


que isso será importante no contexto internacional.

0 Peter Townsend ${ }^{2}$ me pediu a coisa, e me senti fe-

liz em poder fornecer material tão importante.

(CLARK; OITICICA, 1998, p. 130; carta de

\section{3/12/1969)}

O fato de o editor da revista ter solicitado o texto a Oiticica não garantiu a publicação. Em fevereiro de 1970, Oiticica, já de volta ao Rio de Janeiro, atualiza Lygia Clark sobre o andamento deste projeto: "Guy escreveu dizendo que o Studio International recebeu o artigo e que vai me escrever; acho que vão mesmo publicá-lo [...] Tomara que saia logo o troço do Studio, porque vai pesar, e muito." (CLARK; OITICICA, 1998, p. 138139; carta de 19/2/1970) E o assunto reaparece na correspondência com Clark até meados de 1970: "Creio que a coisa do Studio sai em junho ou julho (que demora bem inglesa!)". (CLARK; OITICICA, 1998, p. 150 ; carta de $16 / 5 / 1970$ )

O texto é uma elaboração teórica das experiências feitas por Oiticica na Whitechapel Gallery, inspirada pelo livro Fenomenologia da Percepção de Merleau-Ponty, sem qualquer intenção de rigor na leitura do filósofo francês. Assim como fez com Nietzsche, Bergson ou Marcuse, Oiticica captava dos filósofos o que Ihe servisse como impulso, e constituía, a partir daí, sua própria argumentação e elaboração de conceitos. De Merleau-Ponty, Oiticica incorporou a refutação da dicotomia entre consciência e mundo, e o estabelecimento do corpo como cerne da relação do sujeito com o mundo. Não é o intelecto que propiciará essa relação, e sim a percepção sensorial.

Ao longo de The Senses Pointing..., Oiticica defende uma arte que recrudesça a capacidade do sujeito de se saber parte do mundo, a partir da percepção sensorial, compreendendo-se também como perceptível. A arte almejada por Oiticica e estruturada a partir do conceito de Crelazer, por consequência, não admite o quadro de parede, que ao longo da história da arte fez o papel de janela que separa o sujeito do mundo exterior $^{3}$. O quadro reforça uma noção de sujeito cartesiano, que se coloca no mundo a partir da relação intelectual com o exterior, a partir de um "lado de dentro", onde residiria a consciência, cerne do sujeito pensante, e o "lado de fora", que é o mundo. Na pintura figurativa, o espectador olha a representação de mundo, por exemplo, uma paisagem (CAUQUELIN, 2007), separado do mundo duas vezes: uma pela re- 
presentação e outra pelo modelo de janela que estabelece dois âmbitos separados, interior e exterior. Daí o primeiro parágrafo do texto de Oiticica apresentar o problema como a necessidade de evolução da arte a partir de uma

consciência de totalidade, da relação indivíduomundo como uma ação inteira [...] distante do super intelectualista foco visual [... ol olfato-visãopaladar-audição e tato misturam-se e são 0 que Merleau-Ponty chamou de "simbólica geral do corpo", onde todas as relações de sentido são estabelecidas em um contexto humano, como um "corpo" de significações e não a soma de significações apreendidas por canais específicos. (OITICICA, 2006 [1969]; tradução da autora)

A expressão usada por Merleau-Ponty é, na verdade, "simbólica geral do mundo." 4 Inconscientemente ou escrevendo a partir de uma leitura prévia, sem consultar o texto de Merleau-Ponty, a troca da palavra mundo pela palavra corpo revela pressupostos da obra de Oiticica a partir de 1968: a totalidade sujeito-mundo, o mergulho do corpo na experiência espaço-temporal, a obra de arte como sendo o dia a dia, as vivências cotidianas.
Oiticica estende a síntese perceptiva, discutida por Merleau-Ponty, a várias áreas do comportamento humano: o social, o político, o estético etc. E quem efetuará essa síntese é o corpo, e não o intelecto distanciado do mundo. Comportamento estético não-repressivo e comportamento político não-repressivo fazem parte do mesmo corpo de significações: "a apreensão e a ação não podem ser isoladas, e a ideia analítica dos sentidos vira uma metáfora, também para expressar a complexidade do comportamento humano." (OITICICA, 2006 [1969]) Nesta passagem, Oiticica contrapõe análise e síntese. A ideia analítica de sentidos é a divisão da percepção em cinco itens isolados, um para cada sentido. A síntese é a compreensão de que eles funcionam juntos. Segundo Merleau-Ponty, assim como um binóculo une duas imagens monoculares, o corpo sintetiza "imagens" fornecidas por cada sentido 5 . A partir desse entendimento do corpo como um todo perceptivo, Oiticica sugere que não se pode analisar, no sentido de dividir, o comportamento humano em campos separados, como se ética, estética, política etc. pudessem ser dissociadas no comportamento do mesmo sujeito. ${ }^{6}$

Paula Braga, Os sentidos e a urgência de transformação. 


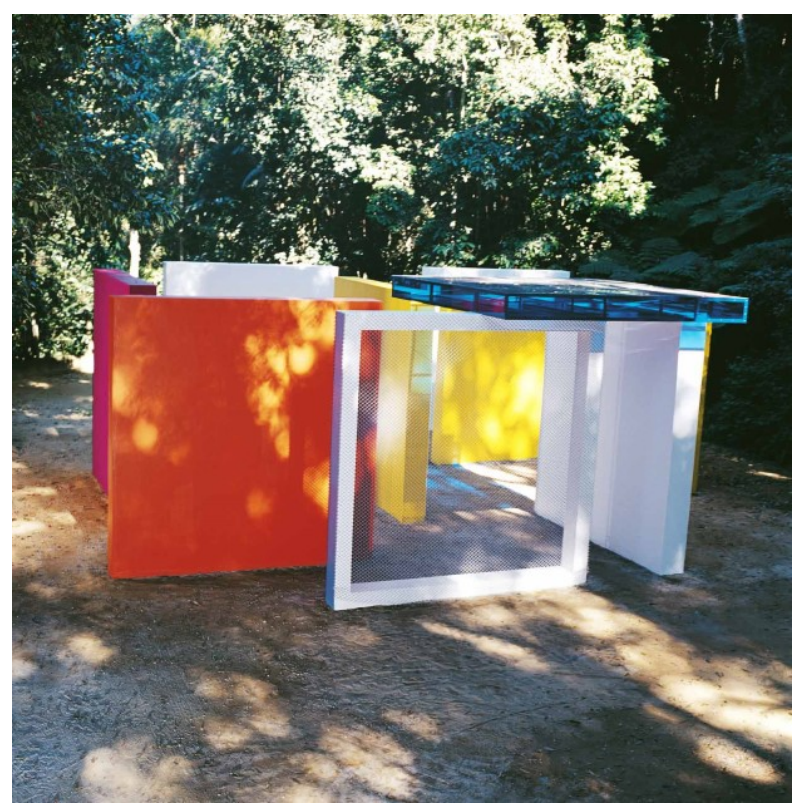

Fig. 1 - Hélio Oiticica, Penetrável Magic Square no. 5, 1978-2000, Museu do Açude, Rio de Janeiro.

(Foto: Cesar Oiticica Filho) 
Depois de apresentar o conceito de comportamento como totalidade, o texto The Senses Pointing Towards a New Transformation segue para a proposta de transformação do artista, que deixa de ser o "sublime gerador de forças criativas e receptor delas, ele mesmo os polos/postes (OITICICA, 2006 [1969]) do mundo significativo estrutural proposto por suas criações." Este artista tradicional impunha ao comportamento humano a estrutura de um mundo metafórico, criado por ele (como, por exemplo, uma paisagem). A nova posição do artista é aquela que compreende que as estruturas criadas pelo artista "crescem do mundo comportamental, depois de um longo processo de dissolução de 'atos do viver humano' $\rightarrow$ o destino dos atos do viver humano ocorrem sem esforços sublimatórios intermediários, conflitos transcendentais ou metas ideais." (OITICICA, 2006 [1969]) Provavelmente incompreensível para os editores da Studio International em 1969, essa passagem torna-se mais clara quando lida em retrospecto, e sabendo que o termo "propor propor", presente nas páginas finais do texto, será usado em outros contextos da escrita de Oiticica para explicar o papel do artista: propositor de condições para que o sujeito se torne o inventor de seu dia a dia; incitador de estados de invenção.
O artista deve propor as estruturas, também chamadas de proposições ambientais, que possibilitarão vivências criativas e sintetizadoras, no sentido de manter a relação sujeito-mundo tão total quanto o resultado do trabalho conjunto de todos os sentidos do corpo. Assim como Merleau-Ponty discute a possibilidade de ver um som, Oiticica propõe algo como um comportamento estético-político com a apresentação de Crelazer, que é, ao mesmo tempo, conceito filosófico e proposta artística na produção de Hélio Oiticica. O Crelazer (Creleisure), também chamado de Crecomportamento (Crebehaviour), incitaria o "germe" do descondicionamento dos comportamentos:

\section{não uma criação-de-objeto através do comporta- mento, nem a transformação de atos de vida em atos criativos, o que seria uma ideia simplista: nes- te caso, as condições seriam só Utopias distantes, mas, se [vindos] de dentro do comportamento condicionado, os elementos começam a crescer como necessidades, como germes que explodem do centro mesmo dos conflitos?}

A partir do conflito entre comportamento condicionado e comportamento descondicionado, Crebehaviour incita a explosão de "germes", palavra indissociável da ideia de

Paula Braga, Os sentidos e a urgência de transformação. 
contaminação: ao explodir, o novo comportamento descondicionado lançaria esporos do germe em todas as áreas do viver, espaIhando uma contaminação transformativa dentro da qual processos da arte e processos de vida tornam-se indistinguíveis.

O conflito entre comportamento condicionado e descondicionado pode ser representado pelo lazer. Oiticica lia Herbert Marcuse pelo menos desde $1968^{8}$ e a teoria desenvolvida em Eros e Civilização sobre trabalho e lazer alienados e seus contrapontos, o trabalho e lazer libidinais ${ }^{9}$ foram bem aproveitados para o desenvolvimento do conceito de Crelazer, uma proposta de fazer artístico que incita a um comportamento que toma para si a posse do tempo, processo que ao invés de correr no tempo da produção, corre em um tempo-estético, de construção de um mundo próprio, em oposição à aceitação passiva do mundo do espetáculo:

em minha evolução, cheguei ao que chamo de crelazer. Para mim o clássico conflito lazer-alienação gerando a ideia de lazer alienado como representado no mundo moderno ocidental seria atacado como conseqüência direta dessa absorção de processos da arte em processos de vida. Crelazer é 0 lazer não-repressivo, oposto do pensamento do lazer opressivo diversivo. (OITICICA, 2006 [1969])

Marcuse não é explicitamente citado em The Senses Pointing..., mas em carta a Lygia Clark, Oiticica ressalta para a amiga a confluência entre um trecho de The senses pointing... e as ideias de um "livro recente de Marcuse." Nessa carta, Oiticica transcreve para Lygia Clark um trecho de The Senses Pointing..., traduzindo-o para português:

\section{as experiências mais recentes de Lygia Clark a con- duziram para proposições fascinantes, e descobriu que certamente a sua comunicação terá que ser mais uma introdução a uma prática que chama ce- lular de pessoa a pessoa, um diálogo corporal im- provisado que se pode expandir numa total cadeia criando como que um todo biológico ou que eu chamaria de creprática. (CLARK; OITICICA, 1998, p. 150; carta de 27/6/1969)}

Após apresentar o conceito de Crelazer, Oiticica reflete sobre a inadequação do museu ou galeria como local para desenvolver proposições como Crelazer.

Recentemente, uma nova exigência e importantes decisões me acometeram: na experiência que proponho, como na prática de crelazer. A impossibilidade de "exibir" objetos como parte dessa ideia, 


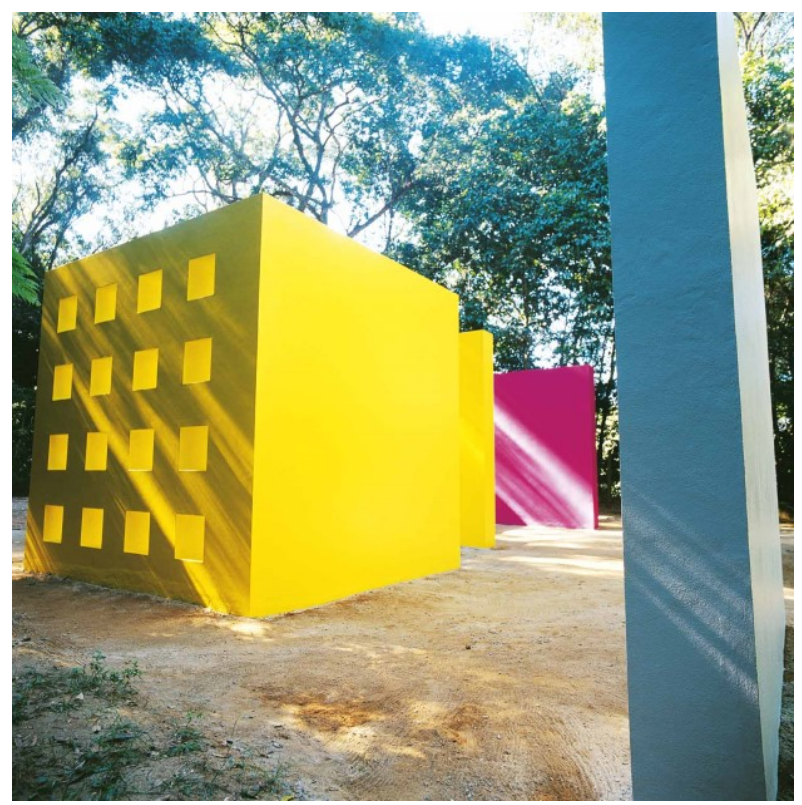

Fig. 2 - Hélio Oiticica, Penetrável Magic Square no. 5, 1978-2000, Museu do Açude, Rio de Janeiro.

(Foto: Cesar Oiticica Filho) 


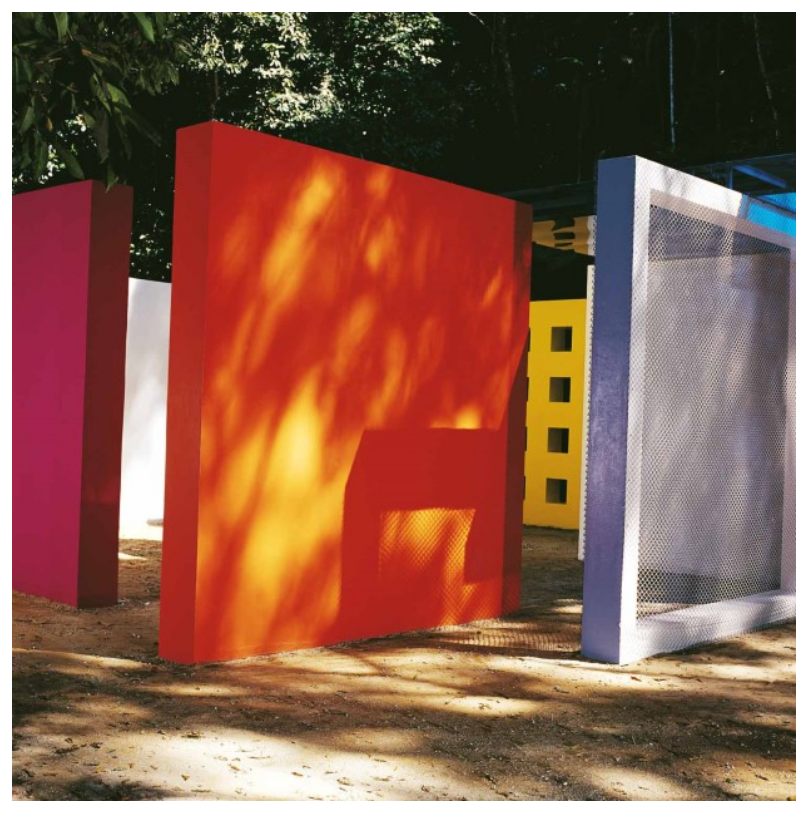

Fig. 3 - Hélio Oiticica, Penetrável Magic Square no. 5, 1978-2000, Museu do Açude, Rio de Janeiro.

(Foto: Cesar Oiticica Filho) 
em galerias ou museus, tornou-se evidente: tive

um vislumbre definitivo disso no experimento Whitechapel em fevereiro-abril de 1969, em Londres.

Para mim, aquilo foi mais um experimento do que uma exposição (eu propus coisas ao invés de expôlas). Mas toda a evolução que apresentei lá leva a essa condição: a imposibilidade de experimentos em galerias ou museus - ao ar-livre ainda poderiam valer, dependendo de suas relações e razões.

(OITICICA, 2006 [1969]; tradução da autora)

O final do artigo enviado para a Studio International apresenta a ideia do autoteatro, que seria desenvolvida ao longo dos anos 1970, culminando nos labirintos públicos, em praças e parques, como abrigos para o Crelazer. $\mathrm{O}$ artista proporia apenas a estrutura do labirinto, e cada um faria sua autoperformance. Um exemplo de labirinto público é o Magic Square \#5, montado postumamente em Inhotim e no Museu do Açude. (BRAGA, 2013)

Os grandes experimentos coletivos grupais deveriam poder contar com lugares permanentes onde experimentos não estariam unidos à ideia de "experimento-espetáculo". Deveria, antes, concentrarse em uma experiência que propõe crescimento interior: propor propor, que poderia levar a caminhos

fascinantes. (OITICICA, 2006 [1969]; tradução da autora)

Como retomar a explosão dos germes de força de vida na arte contemporânea? Não estaríamos hoje necessitando ainda mais de proposições artísticas descondicionadoras do comportamento? Quem já esteve em uma Cosmococa ou em um Magic Square deve ter percebido o constrangimento em vivenciar essas estruturas para além da tomada de uma selfie. Será que perdemos a possibilidade de explosão dos germes da necessidade de relacionamento total com o mundo?

As proposições de Oiticica e Clark aconteceram em um momento de transformação geral dos comportamentos na Europa e América, como proposta ativa e contra-atuante ao risco de alienação que a incipiente sociedade do espetáculo representava. Havia ainda uma bifurcação de caminhos possíveis. A força da contracultura da época era sentida como pulsão emergindo do underground, vindo à luz no festival de Woodstock, nos discursos de Martin Luther King, nas passeatas feministas. Escrito nes-

Paula Braga, Os sentidos e a urgência de transformação. 
sa voltagem, o texto The Senses Pointing... apresenta a proposta de uma nutrição forte para o sujeito da época, quando ainda era possível fomentar "a grande saúde" nietzschiana na sociedade. Comparada a essa potência, a arte relacional dos anos 1990 parece ser uma apática e artificial encenação de tratamento para o paciente que já morreu, e a arte telemática ou de realidade virtual isolam ainda mais o sujeito da relação com o mundo.

O trabalho para o artista contemporâneo será árduo agora que a existência como imagem digital suplantou a experiência sensorial. A reparação exigirá a invenção, pois apenas retomar as propostas artísticas de Oiticica e Clark seria mera diluição. No entanto, o caminho conceitual apontado em The Senses Pointing... contém antídotos aos danos causados pela virtualização da vida. Discutí-lo, e finalmente publicá-lo, fortalece os fios soltos deixados por Oiticica: a valorização do corpo e da totalidade perceptiva, a compreensão do comportamento como síntese, inseparável, entre ética, estética e política. O mal-estar geral da sociedade brasileira em 2019 é sintoma de que os germes estão prestes a explodir: "algo espreita a possibilidade de se manifestar e aguarda $\rightarrow$ ultraguarda."10

\section{Notas}

${ }^{1}$ Há quatro versões desse texto no Arquivo HO, desde um manuscrito até a versão final. Trabalhamos com essa última, que explicita, ao final, a data de escrita (18 a 25 de julho) e a data das revisões (novembro e dezembro de 1969). A versão final tem um agradecimento a Guy Brett pela revisão do texto.

2 Peter Townsend foi editor da Studio International entre 1965 e 1975.

${ }^{3}$ Para uma discussão sobre o quadro e a janela, ver BELTING, 2015.

${ }^{4}$ A "simbólica geral do mundo" aparece em um capítulo em que o filósofo discorre sobre a cor e o trabalho interligado dos sentidos (ouvir a cor, ver o som etc.), cf. MERLEAU-PONTY, 2006, p. 317 (segunda parte, "O mundo percebido/ O Sentir").

${ }^{5}$ MERLEAU-PONTY, 2006, p. 314-5. "O objeto intersensorial está para o objeto visual assim como o objeto visual está para as imagens monoculares da diplopia, e na percepção os sentidos comunicam assim como na visão os dois olhos colaboram (...) enquanto meu corpo é não uma soma de órgãos justapostos, mas um sistema sinergético do qual todas as funções são retomadas e ligadas no movimento geral do ser no mundo (...) Meu corpo é a textura comum de todos os objetos e é, pelo menos em relação ao mundo percebido, o instrumento geral de minha 'compreensão'."

${ }^{6}$ Essa idéia fica mais clara quando confrontamos The Senses Pointing... com um texto de maio de 1968, apresentado no simpósio do MAM-RJ, Critério para o julgamento das obras de arte contemporânea", no qual Oiticica afirma a síntese de todos os problemas (estéticos, éticos, políticos, sociais...). (OITICICA, 2006 [1968]

7 verbo "vir", entre colchetes, foi adicionado pela autora. 
${ }^{8}$ Em carta para Lygia Clark de 8/11/1968, Oiticica define a atuação artística a partir das teorias de Marcuse. cf. CLARK; OITICICA, 1998, p. 74-75.

${ }^{9}$ MARCUSE, 1999, p. 60 . "O controle básico do tempo de ócio é realizado pela própria duração do tempo de trabalho, pela rotina fatigante e pela mecânica do trabalho alienado, o que requer que o lazer seja um relaxamento passivo e uma recuperação de energias para o trabalho. (...) Não se pode deixar o indivíduo sozinho, entregue a si próprio. Pois se tal acontecesse, com o apoio de uma inteligência livre e consciente das potencialidades de libertação da realidade de repressão, a energia libidinal do indivíduo, gerada pelo id, lançarse-ia contra as suas cada vez mais extrínsecas limitações e esforçar-se-ia por abranger uma cada vez mais vasta área de relações existenciais, assim arrasando o ego da realidade e de seus desempenhos repressivos."

10 OITICICA, Sem título, PHO 0384/69. Publicado como “LDN" (abreviação de "London”) em OITICICA, 1986, p. 117.

\section{Referências}

BELTING, Hans. A janela e o muxarabi: uma história do olhar entre Ocidente e Oriente. In ALLOA, Emmanuel (Org.). Pensar a imagem. Belo Horizonte: Autêntica Editora, 2015.

BRAGA, Paula. Hélio Oiticica: singularidade, multiplicidade. São Paulo: Perspectiva, 2013.

CAUQUELIN, Anne. A invenção da paisagem. São Paulo: Martins Fontes, 2007.
CLARK, Lygia; OITICICA, Hélio. Lygia Clark - Hélio Oiticica: Cartas, 1964-74. (Organização de Luciano Figueiredo). Rio de Janeiro: UFRJ, 1998.

MARCUSE, Herbert. Eros e Civilização: uma interpretação filosófica do pensamento de Freud. Rio de Janeiro, LTC, 1999.

MERLEAU-PONTY, Maurice. Fenomenologia da Percepção. (Tradução de Carlos Alberto Ribeiro de Moura). São Paulo: Martin Fontes, 2006.

OITICICA, Hélio. The Senses Pointing towards a New Transformation. Arquivo HO 0486/69. Rio de Janeiro: Projeto HO, 2006.

OITICICA, Hélio. Sem título. Arquivo HO 133.68. Rio de Janeiro: Projeto HO, 2006.

OITICICA, Hélio. Aspiro ao grande labirinto. Rio de Janeiro: Rocco, 1986. 